\title{
The Research on Customers' satisfaction on Rough Set in Vegetable Quality Tracking System and its Influencing Factors
}

\author{
Boming $\mathrm{Xu}^{\mathrm{a}}$, Shifeng $\mathrm{Liu}^{\mathrm{b}}$ \\ School of Economics and Management, Beijing Jiaotong University, Beijing 100044, China \\ a14120579@bjtu.edu.cn, bshfliu@bjtu.edu.cn
}

\begin{abstract}
Keywords: management science and engineering; rough set; satisfaction; big data; vegetable quality tracking system.
\end{abstract}

\begin{abstract}
The people of China are paying more and more attention to food safety problem, vegetables as an indispensable part of food has become the focus of the food safety supervision. This paper based on the survey data of used vegetable quality traceability system user of Beijing, using rough set theory to analyze the key factors affecting customers on the satisfaction evaluation of the project. The results show that traceability system convenience, the authority of traceability information, traceability information integrity and satisfaction of quality problem four variables are the key factors influencing the vegetables quality traceability system satisfaction.
\end{abstract}

\section{Introduction}

With the continuous improvement of people's living standard safety awareness and frequent accidents in vegetable safety, consumer pay more and more attention to vegetable safety. Whether agricultural market, supermarket or retailers, cannot satisfy the consumers' right to know of vegetables quality information [1]. In this case, increasing the security risk and economic risk of consumers to buy agricultural products.

Many experts and scholars did a thorough research on agricultural products quality tracking system. Their research focuses on the design and implementation of agricultural products quality tracking system [2]. But in the consumer satisfaction of agricultural products quality tracking system using, lack of in-depth research.

Now, the using of agricultural products quality tracking system is not common in China. The study of this paper analyses the key factors that effect of people satisfaction for agricultural products quality tracking system. This study have great significance to the development of agricultural products quality tracking system.

\section{The basic concept of rough set theory}

\subsection{The basic concept.}

Rough set theory has been put forward by Polish scholar Z.P in 1982, it can effectively analyze and deal with imprecise, inconsistent, incomplete and so on all kinds of incomplete information. The object of researched by Social Science is very complex, and the researchers collect data often contains noise, inaccurate or incomplete. The method of Statistical regression analysis was effective to some specific issues, but it need of some additional information or prior knowledge of data. And the effect is not ideal that using assumptions of pure mathematics to eliminate or avoid the uncertainty [3].

On the contrary, the method of rough set has become an effective way on dealing with complex system. The most significant difference that the method of rough set with the probability method, fuzzy set and evidence theory method is need not provide any other priori information except data collection that using for deal with problem [4]. The areas of the rough set including rough set models to expand research, knowledge acquisition and reduction, knowledge of the uncertainty measurement, etc. And knowledge acquisition theory is one of the core problems in rough set research. 
Due to the particularity of vegetable quality traceability system, the research data usually has large sample space, various properties and poor integrity, so this paper choose the rough set theory to analyze the key factors that affecting customer's satisfaction on using agricultural products quality tracking system.

\subsection{Information System}

Information System can be made by quad IS $=(\mathrm{U} . \mathrm{A}, \mathrm{Va}$. f). For $\mathrm{U}=\{\mathrm{u} 1, \mathrm{u} 2, \mathrm{u} 3 \ldots \mathrm{Un}\}$, it is called domain, it is a limited and not empty set of objects, and the elements of $U$ are called objects. $A=\{a 1$, a2, a3......an $\}$ also is a limited and not empty set, the elements of A are called attribute, and $A=C \cup D, C \cap D \neq \Phi$.C and $\mathrm{D}$ respectively referred to as the condition attributes set and the decision attribute set. $\mathrm{Va}$ is called the attribute of a domain. For $\mathrm{f}: U \times A \rightarrow V$, it is called information function .For $\forall \mathrm{a} \in A 、 \forall \mathrm{x} \in \mathrm{U}, \mathrm{f}(\mathrm{x}, \mathrm{a}) \in \mathrm{V}_{\mathrm{a}}$, it specifies the attribute values of every object in the $\mathrm{U}[5]$.

\subsection{Knowledge reduction}

Given a knowledge base such as $\mathrm{K}=(\mathrm{U}, \mathrm{S})$ and an equivalence relation of knowledge base such as $P \subseteq S$, for any $G \subseteq P$, if $G$ is independent and IND (G) = IND (P), says that $G$ is a reduction of $P$, remember to $G \in R E D(P)$. The RED (P) says a collection of all the reduction of $\mathrm{P}$ [6].

\section{The data collection and analysis}

\subsection{The data collection}

The data of this paper was collected by our group through investigating the users of vegetable quality traceability system in July 2015 in Beijing. The survey content involves the user's individual characteristics, whether take care of vegetables quality and whether satisfied to vegetable quality traceability system. We gave out 196 survey questionnaires, and recycling questionnaire 196.The valid questionnaires that used vegetable quality traceability system is 126 . Recycling effective rate is 89.36\%.

\subsection{To set up information system}

Apply the collected many related information to establish information system that is about user satisfaction of vegetable quality tracking system. C show condition attributes, it made by C1, C2, C3... C22, details are shown in table 1. D said the decision attribute, namely the user satisfaction of vegetable quality tracking system. We are going to take three values for decision attribute. The satisfaction of consumers can be divided into three categories, the first major categories for satisfied, the second categories is not satisfied, the third major categories for don't care. And values for $\mathrm{d} 1=1$, $\mathrm{d} 2=2, \mathrm{~d} 3=3$. So $\mathrm{C}=\{\mathrm{c} 1, \mathrm{c} 2, \mathrm{c} 3 \ldots . . \mathrm{c} 22\}, \mathrm{D}=\{\mathrm{d} 1, \mathrm{~d} 2, \mathrm{~d} 3\}, \mathrm{A}=\{\mathrm{c} 1, \mathrm{c} 2, \mathrm{c} 3 \ldots . . \mathrm{c} 22, \mathrm{~d} 1, \mathrm{~d} 2, \mathrm{~d} 3\}$.

Table 1 Conditional attribute

\begin{tabular}{|c|c|c|c|}
\hline $\begin{array}{l}\text { variable } \\
\text { Name }\end{array}$ & $\begin{array}{l}\text { Variable } \\
\text { Definition }\end{array}$ & $\begin{array}{l}\text { Variable } \\
\text { Name }\end{array}$ & $\begin{array}{l}\text { Variable } \\
\text { Definition }\end{array}$ \\
\hline $\mathrm{c} 1$ & $\begin{array}{l}\text { whether take care of vegetables } \\
\text { quality and safety }\end{array}$ & c12 & the system whether is convenient \\
\hline c2 & $\begin{array}{l}\text { whether know vegetable quality } \\
\text { tracking system }\end{array}$ & c13 & the convenience wether is important \\
\hline c3 & education background & c14 & how to make the system more convenient \\
\hline c4 & economic income & c15 & $\begin{array}{l}\text { the quality traceability information whether is } \\
\text { authoritative }\end{array}$ \\
\hline c5 & how old are you & c16 & the authority wether is important \\
\hline c6 & the place of buying vegetables & c17 & traceability information whether is comprehensive \\
\hline c7 & whether vegetables quality tracking & c18 & the comprehensive whether is important \\
\hline c8 & whether increase consumption & c19 & $\begin{array}{l}\text { what information should be comprehensive } \\
\text { traceability }\end{array}$ \\
\hline c9 & whether improve the quality of life & c20 & whether had vegetables quality problems \\
\hline c10 & $\begin{array}{l}\text { what is the mothed of vegetables } \\
\text { quality traceability }\end{array}$ & c21 & $\begin{array}{l}\text { whether satisfied for the results of the vegetables } \\
\text { quality problems }\end{array}$ \\
\hline c11 & $\begin{array}{l}\text { what is the name of quality } \\
\text { traceability system }\end{array}$ & c22 & $\begin{array}{c}\text { whether is important to the processing results are } \\
\text { satisfied }\end{array}$ \\
\hline
\end{tabular}




\subsection{Completing missing data}

In practice, most of the information collected by the researchers is often incomplete and have defects, commonly the information systems of containing missing data is called incomplete information system. If we directly deleted the missing data from the table, will cause the waste of resources, and will be lost information hidden in the data. In this paper, the established information system is not perfect information system, so we need to swallow the default values. This paper adopts a filling algorithm called "Conditioned mean Completer". The method use which is same as the current lost values of decision attribute object of all the objects in average to fill the missing attribute value, the specific calculation steps such as shown in table 2 in $\mathrm{f} 1, \mathrm{f} 2$ cell.

Table 2 Incomplete information system

\begin{tabular}{cccc}
\hline $\mathrm{U}$ (consumers) & Condition attributes C1 & Condition attributes C4 & Decision attribute D \\
\hline $\mathrm{X} 1$ & 5 & 4 & 1 \\
$\mathrm{X} 2$ & $\mathrm{f} 1=(5+3) / 2=4$ & 4 & 1 \\
$\mathrm{X} 3$ & 3 & $\mathrm{f} 2=(4+4) / 2=4$ & 1 \\
\hline
\end{tabular}

Note: the initial value of $\mathrm{f} 1$ and $\mathrm{f} 2$ is empty.

\section{Data reduction and analysis results}

In the process of data mining, some of the condition attribute is not the key information, we call these condition attribute as redundant attributes. Attribute reduction is refers to maximum reduce redundant attributes under the condition of the knowledge classification ability unchanged, so as to simplify the original system. In this paper, using Rosetta software provided called Johnson algorithm to reduce data, the final results as shown in table 3.

Table 3 Reduction results

\begin{tabular}{|c|c|c|c|c|}
\hline $\begin{array}{l}\text { Information statistics } \\
\text { (decision table) }\end{array}$ & \multicolumn{4}{|c|}{ Reduction results } \\
\hline consumer satisfaction & \multicolumn{4}{|c|}{$\begin{array}{l}\text { traceability system convenience, the authority of traceability information, } \\
\text { traceability information integrity, satisfaction of quality problem }\end{array}$} \\
\hline \multirow{2}{*}{\multicolumn{5}{|c|}{$\begin{array}{l}\text { According to the results of the above reduction, analyzing the key factor data. The results as } \\
\text { shown in table } 4 \text {. } \\
\text { Table } 4 \text { Farmer satiation summary }\end{array}$}} \\
\hline & & & & \\
\hline User & Category & Satisfied & Unsatisfied & Just as well \\
\hline \multirow{3}{*}{$\begin{array}{l}\text { traceability system } \\
\text { convenience }\end{array}$} & convenient & $57.6 \%$ & $20.80 \%$ & $1.60 \%$ \\
\hline & not convenient & $6.40 \%$ & $5.60 \%$ & $0.00 \%$ \\
\hline & be unaware of & $2.40 \%$ & $4.80 \%$ & $0.80 \%$ \\
\hline \multirow{3}{*}{$\begin{array}{l}\text { the authority of } \\
\text { traceability information }\end{array}$} & authoritative & $41.60 \%$ & $15.20 \%$ & $0.00 \%$ \\
\hline & not authoritative & $21.60 \%$ & $7.20 \%$ & $1.60 \%$ \\
\hline & be unaware of & $3.20 \%$ & $8.80 \%$ & $0.80 \%$ \\
\hline \multirow{3}{*}{$\begin{array}{l}\text { traceability information } \\
\text { integrity }\end{array}$} & comprehensive & $56.80 \%$ & $18.40 \%$ & $0.80 \%$ \\
\hline & incomplete & $8.00 \%$ & $9.60 \%$ & $0.00 \%$ \\
\hline & be unaware of & $1.60 \%$ & $3.20 \%$ & $1.60 \%$ \\
\hline \multirow{3}{*}{$\begin{array}{l}\text { satisfaction of quality } \\
\text { problem }\end{array}$} & satisfying & $51.20 \%$ & $17.60 \%$ & $0.80 \%$ \\
\hline & dissatisfied & $15.20 \%$ & $13.60 \%$ & $0.00 \%$ \\
\hline & be unaware of & $0.00 \%$ & $0.00 \%$ & $1.60 \%$ \\
\hline
\end{tabular}

Based on the previous theoretical and empirical research results, this study has the following four findings:

First, vegetable quality traceability system is more convenient and the satisfaction of people are higher. This means that, convenience is very important for vegetable quality tracking system.

Second, the information of agricultural products quality traceability is more authority, the satisfaction of consumer higher. Compared with no authoritative test information, vegetables which has authoritative quality inspection information is more popular with consumers. 
Third, the information of vegetable quality traceability more comprehensive, the higher the satisfaction of consumer. This suggests that consumers is not only concerned about the safety of vegetable production also focus on the information of agricultural materials supplier, the information of circulation and distribution in the process and so on.

Fourth, the satisfaction of vegetables quality problem processing results, but also one of the key factor that determine whether consumers satisfied with vegetables quality traceability system. So compared with use the finite energy and money to brand promotion, enterprise should safeguard the rights and interests of consumers.

\section{Summary}

In this paper, we used the method of rough set to discuss the key factors that influence the consumers' satisfaction with vegetables quality traceability system. The results show that traceability system convenience, the authority of traceability information, traceability information integrity and satisfaction of quality problem four variables are the key factors influencing the vegetables quality traceability system satisfaction. The construction of vegetable quality traceability system is not only related to vegetable industry healthy and is related to people's life safety and stability [7]. Therefore, this article puts forward suggestions as following:

(1) Promoting the application of vegetable quality tracking system. In the era of the Internet is popular, it is an effective way to alleviate the problem of food safety to strengthen the promotion and popularization of vegetable quality traceability system [8]. And it can provide the reference for other food safety traceability system construction to promote the use of vegetable quality and safety traceability system.

(2) The regulators need to actively participate in the construction of the vegetable quality tracking system. The construction of vegetable quality traceability system is not only beneficial to the development of the enterprise and good for food regulatory supervision. The participation of regulators also can effectively prevent the incidents of vegetable quality and safety.

\section{References}

[1] Yunyun Dai. The countermeasure analysis of vegetable quality and safety management in China [J]. China Population Resources and Environment.2013, S2:66-69.

[2] Haiting Liao, Yumin Nie. The research progress of vegetable safety traceability system [J]. Journal of Shandong Agricultural University. 2014, 02: 316-320.

[3] Zadeh LA. Fuzzy sets [J]. Information and Control. 1965, 8 (3):338-53.

[4] Zdzislaw Pawlak, Jerzy Grzymala-Busse, Roman Slowinski, Ziarko W. Rough sets [J]. Communications of the ACM. 1995, 38(11):88-95.

[5] Yao Y. The superiority of three-way decisions in probabilistic rough set models [J]. Information Sciences. 2011, 181(6):1080-96.

[6] Zhengyao Hu. The research and application of data reduction which based on rough set theory [D]. Master, Wuhan Science and Technology University, 2012.p.12.

[7] Jinshu Wang, Xiaoling Cheng, Yi wang. The construction and economic evaluation of vegetable quality tracking system [J]. Journal of Changjiang Vegetables, 2012, 15:1-3.

[8] Lei Yang. The official opening of Beijing vegetable product quality traceability system [N]. China Quality Daily, 2006-10-10002. 